\title{
Analysts' Cash Flow Forecast Accuracy and Recommendation Profitability
}

\author{
Shanshan Pan \\ University of Houston-Clear Lake
}

We examine whether analysts who supplement their earnings forecasts with more accurate cash flow forecasts generate more profitable recommendations. Previous research using consensus cash flow forecasts, or the issuance of cash flow forecasts fails to document a significant relation between analysts' cash flow forecasts and their stock recommendation performance. We argue that analysts' cash flow forecasts differ in quality and hypothesize that the relative accuracy of an individual analyst's cash flow forecasts is positively associated with the profitability of that analyst's stock recommendations. We find that when analysts issue both earnings and cash flow forecasts for a firm, cash flow forecast accuracy predicts stock recommendation profitability even after controlling for earnings forecast accuracy. Our findings are robust to the use of instrumental variables and the use of recommendation change in the analysis. Whether analysts also issue sales forecasts and/or long-term growth forecasts does not affect the results.

Keywords: Financial Analysts, Cash Flow Forecasts, Earnings Forecasts, Forecast Accuracy, Stock Recommendations

\section{INTRODUCTION}

We examine whether analysts who supplement their earnings forecasts with more accurate cash flow forecasts generate more profitable recommendations. Given analysts are more likely to supplement earnings forecasts with cash flow forecasts when cash flows are incrementally useful to earnings in firm valuation (Ali, 1994; Dechow, 1994; Defond and Hung, 2003), supplementary cash flow forecasts can be expected to affect their own stock recommendation performance. However, research on whether analysts' cash flow forecasts play any role in their stock recommendations is rather limited. Duboisée de Ricquebourg and Clacher (2017) show that analysts' consensus stock recommendations do not seem to be informed by their consensus cash flow forecasts in a sophisticated manner to earn abnormal returns. While focusing on analysts' long-term growth forecasts and stock recommendations, Jung et al. (2012) document that market returns to stock recommendation revisions accompanied by cash flow forecasts are negative. ${ }^{1}$ These findings seem to suggest that despite market demand for cash flow forecasts in firm valuation (Defond and Hung, 2003), analysts are unable or unwilling to translate their own cash flow forecasts into profitable stock recommendations.

We argue that the consensus cash flow forecasts or the mere existence of the cash flow forecasts may not capture the wide spectrum of the cash flow forecast quality across individual analysts. Cash flows are typically more volatile than earnings; they are more difficult to forecast than earnings (Ertimur and 
Stubben, 2005; Givoly et al., 2009). On one side of the spectrum, analysts' cash flow forecasts can be simple extensions of their earnings forecasts through mechanical adjustment for depreciation and other non-cash items (Givoly et al., 2009). On the other side of the spectrum, high quality cash flow forecasts require greater efforts in mapping out the articulation of a complete set of the financial statements, namely income statement, balance sheet, and statement of cash flows (Call et al., 2009). ${ }^{2}$ Consequently, using the consensus cash flow forecasts or the issuance of the cash flow forecasts may be insufficient to document the incremental benefit accrued to superior cash flow forecasters in making investment recommendations. Instead, we propose to examine whether the relatively higher accuracy of an individual analyst's supplemental cash flow forecast is associated with the higher profitability of that analyst's stock.

We hypothesize that, if cash flows are incrementally useful to earnings in assessing a firm's viability (Ali, 1994; Dechow, 1994; Defond and Hung, 2003), then analysts who can supplement their earnings forecasts with more accurate cash flow forecasts enjoy a distinct advantage in firm valuation to produce profitable stock recommendations. However, our prediction may not hold empirically for several reasons. First, previous research has documented that earnings are more accurate when issued together with cash flow forecasts (Pae et al., 2007; Call et al., 2009) and more accurate earnings forecasts are associated with more profitable recommendations (Loh and Mian, 2006; Ertimur et al., 2007). If accurate cash flow forecasts mainly assist analysts in producing accurate earnings forecasts, then analysts' cash flow forecast accuracy may not contribute directly to their superior stock picks beyond their earnings forecast accuracy. Second, if analysts who can forecast earnings more accurately can also forecast cash flows more accurately, then again the relation between cash flow forecast accuracy and recommendation profitability may not be significant after earnings forecast accuracy is controlled for. Pae and Yoon (2012), however, document that forecasting cash flows requires a distinct set of skills and expertise than forecasting earnings. Therefore, earnings forecast accuracy should not completely subsume cash flow forecast accuracy in predicting stock performance. Nonetheless, to the extent these countervailing arguments hold, they would work against finding results supporting our prediction.

Using individual analysts' annual forecasts and recommendations for US firms from the I/B/E/S Detail History database from 1993 to 2014, we identify a sample of 42,578 recommendations with both earnings forecasts and cash flow forecasts issued within 30 days prior to and including the issue date of the recommendations. To test our prediction, we measure stock recommendation profitability as the buy and hold market-adjusted return surrounding individual analysts' stock recommendation date (Ertimur et al., 2007). We also adopt a measure of relative forecast accuracy to control for firm-year effects by mean adjusting the absolute forecast errors (Clement, 1999; Ertimur et al., 2007). We first estimate pooled regressions of market-adjusted stock returns surrounding analysts' stock recommendations on their earnings forecasts accuracy and cash flow forecast accuracy separately. We find that either earnings forecast accuracy or cash flow forecast accuracy is significantly positively related to their stock recommendation profitability. We then estimate a pooled regression of stock recommendation profitability on earnings forecast accuracy and cash flow forecast accuracy together. The results show that while more accurate cash flow forecasts continue to be significantly positively associated with more profitable stock recommendations, the effect of earnings forecast accuracy on recommendation profitability becomes marginal, suggesting that for firms that analysts issue both earnings forecasts and cash flow forecasts, cash flow forecast accuracy dominates earnings forecast accuracy in predicting profitable recommendations.

To alleviate the concern of unobservable analyst characteristics or other omitted variables driving our results, we adopt two instrumental variables to capture exogenous variations in analyst cash flow forecast accuracy: (1) analyst cash flow forecast frequency and (2) analyst cash flow forecast horizon. These instrumental variables affect cash flow forecast accuracy (Pae and Yoon, 2012) but are less susceptible to the endogeneity problem. The estimates from the instrumental variable regressions also suggest that more accurate analysts generate more profitable recommendations. In addition, these results are robust to alternative specification of profitability based on recommendation changes, and to controls for the issuance of sales forecasts and long-term growth forecasts.

Journal of Accounting and Finance Vol. 19(5) 2019113 
Our study therefore contributes to the emerging research on the interplay between analysts' earnings forecasts as inputs and their stock recommendation as outputs (e.g. Bradshaw, 2004; Loh and Mian, 2006; Ertimur et al., 2007; Brown and Huang, 2013). Specifically, our study refines our understanding of the link between analysts' earnings forecasting accuracy and their stock recommendation performance. While previous research has focused on analyst efficiency of translating accurate earnings forecasts into profitable recommendations (Loh and Mian, 2006; Ertimur et al., 2007), we have identified cases where analyst cash flow forecast accuracy plays a more significant role in stock recommendations. Our results suggest that when analysts issue both earnings forecasts and cash flow forecasts, relative cash flow forecast accuracy, not earnings forecast accuracy, contributes to more profitable recommendations. Our study therefore both extends and qualifies prior studies that only examine the role of earnings forecast accuracy in stock performance.

Our study also provides further evidence on the benefit of issuing quality cash flow forecasts to financial analysts. Call et al. (2009) document that more accurate cash flow forecasters are less likely to be fired, suggesting that brokerage firms value cash flow forecasting skills. Our study offers one explanation of why cash flow forecasts have such career significance: accurate cash flow forecasts enable analysts to produce more profitable recommendations - outputs that have significant value to brokerage houses. $^{3}$

Finally, whereas the debate continues over the consensus analyst cash flow forecast quality (Givoly et al., 2009; Call et al., 2013; Givoly et al., 2013), Pae and Yoon (2012) document that individual analyst cash flow forecast quality differs as analysts possess different cash flow forecasting skills and capabilities. Our study extends Pae and Yoon (2012) by showing that this variance in analysts' cash flow forecast quality makes a difference in their own output quality. Taken together with Pae and Yoon (2012), our study suggests that examining analyst cash flow forecasts at the individual level can be another fruitful research avenue to pursue.

Our study is related to but distinct from a concurrent working paper by Duboisée de Ricquebourg and Clacher (2017) that examines the relationship between analyst cash flow forecasts and their stock recommendation profitability. Their study is motivated by Bradshaw (2004), Barniv et al. (2009), Barniv et al. (2010) and focuses on the valuation models that analysts use to translate consensus cash flow forecasts into consensus stock recommendations at the firm level. Our study, however, builds on Loh and Mian (2006) and Ertimur et al. (2007) and investigates whether individual analyst cash flow forecast accuracy matters for recommendation profitability at the analyst-firm-forecast level. Duboisée de Ricquebourg and Clacher (2017) find that based on the consensus cash flow forecasts, analysts do not seem to be able to use these forecasts in a sophisticated manner to generate higher returns for their recommendations. ${ }^{4}$ We, however, document that higher level of cash flow forecast accuracy enables individual analysts to make more profitable stock recommendations.

The remainder of the paper is organized as follows. Section 2 reviews relevant literature and develops our hypotheses. Section 3 lays out the research design for testing our hypotheses. Section 4 describes the sample and presents the results. Section 5 discusses the results for robustness check and additional analysis. Section 6 concludes.

\section{RELATED LITERATURE AND HYPOTHESIS}

\section{Analysts' Earnings Forecast Accuracy and Stock Recommendations}

Extensive research has investigated analysts' earnings forecasts and to a lesser extent their stock recommendations. ${ }^{5}$ However, most of these studies have focused on either one of them in isolation. Francis and Philbrick (1993) and Francis and Soffer (1997) were among the earlier research that examined both analysts' earnings forecasts and stock recommendations. Francis and Philbrick (1993) study whether analysts' earnings forecasts are more optimistic for firms that received less than favorable recommendations from their brokerage house. Francis and Soffer (1997) examine the relative informativeness of analysts' stock recommendations and earnings forecast revisions. Neither examines how analysts transform earnings forecasts into stock recommendations. Such observations led Schipper 
(1991) to call for studies that examine how analysts' earnings forecasts as an input have been used to generate the final products: stock recommendations. However, only until recently has research been undertaken to explore this connection. Bradshaw (2004) was the first to directly examine whether analysts' stock recommendations are consistent with valuation models using their earnings forecasts. The study found little evidence that analysts' recommendations can be explained by residual income valuation models. Instead, analysts seem to use simple heuristics such as PEG model or their long-term earnings growth to make stock recommendations.

Loh and Mian (2006) address the issue of the misalignment of analysts' earnings forecasts with their stock recommendations by pointing out that the conclusion from Bradshaw (2004) is based on consensus forecasts and consensus recommendations. However, individual analysts may differ in their forecasting abilities (Clement 1999; Luo and Xie 2012). As a result, analysts' earnings forecast quality differs across individuals. The quality of their inputs could affect the outcome of their forecasts: stock recommendations. Therefore, they posit that analysts who make more accurate earnings forecasts also generate more profitable recommendations. Adopting a portfolio method based on relative forecast accuracy, they find results that confirm such propositions. A zero-investment strategy that long in the stocks favorably recommended and short in those unfavorable recommended by the most accurate analyst yields statistically significant positive returns. In contrast, following the stock recommendations of analysts in the lowest accuracy quintile yields statistically significant negative returns. The authors attribute such differences in stock recommendation performance to the higher quality inputs by the accurate analysts that facilitate superior stock valuations. Ertimur et al. (2007) extends Loh and Mian (2006) by considering other potentially important determinants of profitability including analyst expertise, conflicts of interests and regulatory environment. Using analyst-firm-forecast level of recommendation returns and relative analyst forecast error, they find that after controlling for expertise, more accurate analysts make more profitable recommendations only if the value-relevance of a firm's earnings is high. In other words, when earnings quality is low, even if analysts can forecast earnings accurately, use of such inputs in the valuation model may not help identify stocks that will produce higher return. In this case, analysts may consider other value relevant factors including cash flow forecasts to assess the investment value of a company's stock. As a result, the superiority of their cash flow forecasts will figure more prominently in the valuation process to aid in the selection of more profitable stocks. Analysts' supplementary cash flow forecast accuracy in relation to their stock recommendation performance is the major focus of this paper.

\section{Analysts' Cash Flow Forecast Accuracy and Stock Recommendations}

While analysts have issued earnings forecasts for over thirty years, only recently have they started issuing operating cash flow forecasts. ${ }^{6}$ DeFond and Hung (2003) were among the first to examine analysts' cash flow forecasts. They suggest that financial analysts issue cash flow forecasts in response to market demand for more value-relevant information. Their analysis shows that analysts are more likely to forecast cash flows when the earnings have a lower association with returns and cash flows become useful in evaluating firms. Further, they find that analysts tend to issue cash flow forecasts for firms with large accruals, more heterogeneous accounting choices, high earnings volatility, high capital intensity, and poor financial health. The results corroborate their hypotheses that when earnings are less useful in assessing firm value, analysts issue cash flow forecasts in response to market demand for value-relevant information. Call, Chen and Tong (2009) find evidence that the issuance of cash flow forecasts is positively associated with earnings forecast accuracy. They argue that when analysts issue cash flow casts together with earnings forecasts, they are more rigorous and structured in their approach. Consequently, analysts that issue cash flow forecasts appear to understand better the implications of current earnings for future earnings.

The above studies suggest that analysts' cash flow forecasts are of sufficient quality to provide additional insights into firm valuation. In contrast, Givoly, Hayn and Lehavy (2009) cast doubts on this proposition. They find that analysts' cash flow forecasts are less accurate than analysts' earnings forecasts and that these forecasts have marginal incremental power in explaining contemporaneous annual stock 
returns. In addition, they find that analysts' cash flow forecasts can be derived by simply adding back depreciation and amortization expense to their own earnings forecasts, therefore questioning the quality of analysts' cash flow forecasts.

Despite the ongoing debate on analysts' cash flow forecast quality (Givoly et al., 2009; Call et al., 2013), recent research has, however, accumulated increasing evidence on the economic significance of analysts' cash flow forecasts in the capital markets. For instance, analysts' cash flow forecasts can curb accrual manipulation by management (McInnis and Collins, 2011), mitigate accrual mispricing (Mohanram, 2014; Radhakrishnan and Wu, 2014), reduce cost of equity capital (Jung 2015), and lower audit risks and audit fees (Mao and $\mathrm{Yu}, 2015$ ). In testing the market implications of analysts' cash flow forecasts, most of these studies use either the presence of cash flow forecasts or cash flow forecast coverage. Their results imply that analysts' cash flow forecasts in the aggregate are of sufficient quality to be provide the market with incremental information. However, these studies do not address whether the quality of cash flow forecasts itself matters to individual analysts in their assessment of firm prospects. ${ }^{7}$

Pae and Yoon (2012) were among the first to focus on analysts' cash flow forecasts at the individual level. They examine the determinants of individual analysts' cash flow forecast accuracy. They find that cash flow forecast accuracy is explained by a different set of factors than is earnings forecast accuracy. Instead of earnings forecasting experience and past earnings forecast accuracy, cash flow-specific forecasting experience and past cash flow accuracy predict current cash flow forecast accuracy. They also find that individual cash flow forecasts cannot be reproduced by simply adding depreciation and amortization expenses to earnings forecasts. Rather, these cash flow forecasts are more accurate than naïve cash flow forecasts that are simple extrapolations of earnings forecasts. The results suggest that analysts exhibit individual differences in their cash flow forecasting abilities and skills. As a result, cash flow forecast accuracy varies across individual analysts.

Because cash flow forecasts require additional costs and effort (Ertimur and Stubben, 2005; Givoly et al., 2009), analysts typically issue cash flow forecasts when accounting, operating and financing characteristics make cash flows more important in firm valuations (Ali, 1994; Dechow, 1994; Defond and Hung, 2003). As a result, analysts who can supplement their earnings forecasts with high quality cash flow forecasts are in a better position to correctly evaluate those firms and make stock recommendations accordingly. Hence our hypothesis as follows:

H1: Analysts' supplementary cash flow forecast accuracy is positively associated with their stock recommendation profitability.

\section{The Effect of Regulatory Reforms}

Our first hypothesis assumes that analysts are willing and able to translate their more accurate cash flow forecasts into profitable stock recommendations. However, research also indicates that analysts' incentives may play a role in their recommendations (Michaely and Womack, 1999 and 2005; Lin and McNichols, 1998; Ke and $\mathrm{Yu}, 2006$ ). In other words, analysts may not base their recommendations on evaluating the intrinsic value estimates relative to current stock prices but rather on other objectives. For instance, analysts may have personal interest in issuing optimistic forecasts to curry favors with management, generating investment banking business for the brokerage firm, hyping the stock to increase brokerage trading volumes, and increasing their compensations and the value of shares that they own (Dugar and Nathan 1995; Lin and McNichols 1998; Das et al., 1998; Dechow et al., 2000). In other words, conflicts of interest affect analysts' recommendations (Michaely and Womack, 1999; Barber, Lehavy, and Trueman, 2007). ${ }^{8}$

Recent years have witnessed regulatory reforms aimed to mitigate analysts' conflict of interests so that analysts' publicly released outputs are less biased. Among the major regulations enacted in the last decade that affected financial analysts included Regulation FD issued by SEC in October 2000, which prohibits firms from selectively disclosing information to analysts and levels the playing field for analysts, and the NASD Rule 2711, Research Analysts and Research Reports, approved by SEC in May, 2002, which aims at enhancing analysts' independence in research. Stock recommendations have 
appeared to be more consistent with their earnings forecast based valuations since the regulatory reforms took effect (Barniv et al, 2009; Chen and Chen, 2009). Ertimur et al. (2007) also document that these regulations strengthens the relation between analysts' earnings forecast accuracy and their stock recommendation profitability for conflicted analysts. We therefore expect that analysts' cash flow forecast accuracy is likely to play a more significant role in generating profitable recommendations in the post regulation period. Hence our second hypothesis:

H2: The relationship between analysts' supplementary cash flow forecast accuracy and their stock recommendation profitability is stronger in the post regulation period.

\section{RESEARCH DESIGN}

We examine whether analyst cash flow forecast accuracy is incrementally useful in generating more profitable recommendations. Following Ertimure et al. (2007), we address this research question by adopting the following model. ${ }^{9,10}$

$$
\begin{aligned}
\text { PFT }= & \beta_{0}+\beta_{1} \text { PMEFA }+\beta_{2} \text { PMCFA }+\beta_{3} \text { EFREQ }+\beta_{4} \text { RECFREQ }+\beta_{5} \text { FIRMEXP }+\beta_{6} \text { LFR }+\beta_{7} \text { NFIRM } \\
& +\beta_{8} \text { BSIZE }+\beta_{9} \text { NANALYST }+\beta_{10} \text { VR }+\beta_{11} \text { SIZE }+\beta_{12} \text { BTM }+\beta_{13} \text { LOSS }+ \text { Industry Effects }+ \text { Year } \\
& \text { Effects }+\varepsilon
\end{aligned}
$$

\section{Dependent Variable}

Recommendation profitability (PFT): Following Ertimur et al. (2007), we estimate value weighted market-adjusted stock returns, $P F T$, over the period from the day before the recommendation date until the earlier of either 30 days or 2 days before the recommendation is revised or reiterated. ${ }^{11,12}$ We go long in the buy recommendations and short in the hold and sell recommendations.

\section{Independent Variables}

Earnings forecast accuracy (PMEFA): Following Ertimur et al. (2007), we measure the relative earnings forecast accuracy of an analyst to all analysts following the same firm and compute the accuracy of earnings forecast $\mathrm{k}$ analyst $\mathrm{i}$ issues for firm $\mathrm{j}$ as PMEFA $=-1 \times \frac{E F A_{i j k}-\overline{E F A}}{\overline{E F A}}$, where $\mathrm{EFA}_{\mathrm{ijk}}$ is the absolute forecast error of earnings forecast $\mathrm{k}$ by analyst $\mathrm{i}$ for firm $\mathrm{j}$. Each earnings forecast $\mathrm{k}$ is issued within 30 days prior to and including the issue date of recommendation $\mathrm{k}$ by analyst $\mathrm{i}$ for firm $\mathrm{j} .{ }^{13} \overline{E F A}$ is the mean absolute forecast error of earnings forecasts that are issued for firm $\mathrm{j}$ during the 90 -day period prior to and including the issue date of earnings forecast $\mathrm{k}$ by analysts that meet the sample selection criteria.

Cash flow forecast accuracy (PMCFA): Consistent with our measure of earnings forecast accuracy, we measure the relative cash flow forecast accuracy of an analyst to all analysts following the same firm and compute the accuracy of cash flow forecast $k$ analyst $i$ issues for firm $j$ as PMCFA $=-1 \times$ $\frac{C F A_{i j k}-\overline{C F A}}{\overline{C F A}}$, where $\mathrm{CFA}_{\mathrm{ijk}}$ is the absolute forecast error of cash flow forecast $\mathrm{k}$ by analyst $\mathrm{i}$ for firm $\mathrm{j}$. Each cash flow forecast $\mathrm{k}$ is issued within 30 days prior to and including the issue date of recommendation $\mathrm{k}$ by analyst $\mathrm{i}$ for firm $\mathrm{j} . \overline{C F A}$ is the mean absolute forecast error of forecasts that are issued for firm $\mathrm{j}$ during the 90-day period prior to and including the issue date of forecast $\mathrm{k}$ by analysts that meet the sample selection criteria.

\section{Control Variables}

We also include the following control variables that prior literature has shown to be associated with stock performance.

Earnings forecast frequency (EFREQ): Prior research has suggested analysts who issue forecasts more frequently for a firm may also exert greater efforts in following the firm (Jacob et al., 1999; Clement and Tse, 2003). As a result, their recommendations can be more profitable. Therefore, we use the 
number of earnings forecasts issued for a firm in a calendar year, $E F R E Q$, to proxy the amount of effort that analysts make in following a firm.

Recommendation frequency (RECFREQ): Analysts who update their recommendations for a firm more frequently are more likely to pay greater attention to the latest development of a firm's competitive environment and business operations (Ertimur et al., 2007). Their recommendations are more likely to result from active research efforts and hence more profitable. We measure recommendation frequency as the number of recommendations issued by analysts for a firm during calendar year $\mathrm{t}$.

Firm-experience (FIRMEXP): Analysts may gain greater understanding of a firm and hence issue more profitable stock recommendations as their forecasting experience for the firm increases. We measure an analyst's firm specific experience, FirmExp, as the number of years through year $\mathrm{t}$ for which an analyst has issued a forecast for a firm (Ertimur et al., 2007; Luo and Xie 2012).

Leader-follower ratio (LFR): Analysts that can issue forecasts more timely may have superior expertise. Following Cooper et al. (2001), we compute the leader-follower ratio, LFR, as the cumulative number of days by which the preceding two forecasts lead forecast $\mathrm{k}$ divided by the cumulative number of days by which the subsequent two forecast follow forecast $\mathrm{k}$. LFR is greater than one for an analyst that is a leader in issuing the forecast.

Number of firms followed (NFIRM): We use NFirm, the number of firms an analyst follows in a calendar year to control for the complexity of analysts' forecasting job as well as the time and resources an analyst devotes to a given firm (Clement, 1999). We expect that the greater the number of firms an analyst follow, the poorer the performance of the stock s/he recommends.

Brokerage size (BSIZE): To control for the resources available to an analyst, we use BSize, the number of analysts employed by the brokerage that an analyst works for during a calendar year to proxy for the size of the brokerage. We expect that larger brokerage firms provide greater resources to their analysts and hence the higher the performance of the stocks their analysts recommend (Clement and Tse, 2003).

Analyst following (NANALYST): We compute NANALYST, as the number of analysts who issue forecasts and recommendations for a firm during a calendar year. Prior literature has shown that analysts tend to follow firms with greater information available (Lang and Lundholm 1996). Better information environment may assist analysts in making more accurate forecasts and profitable recommendations.

Value relevance (VR): Ertimur et al. (2007) has documented that the positive correlation between an analyst's earnings forecast accuracy and stock recommendation profitability is affected by a firm's earnings value relevance. We measure Value relevance (VR) as the adjusted R-square of a rolling 10-year window regression of firms j's 15-month return ending three months after the fiscal year end t on firm j's earnings and change in earnings in fiscal year $t$, where earnings is firm j's income before extraordinary items in fiscal year $\mathrm{t}$, scaled by market value at the end of fiscal year $\mathrm{t}-1$.

In addition, we include the following variables to control for firm characteristics that may affect the performance of the recommended stock.

Firm size (SIZE): We calculate Size as the natural log of a firm's market value at the end of fiscal year $\mathrm{t}-1$.

Book-to-Market (BTM): We compute BTM as firm's book value of equity in fiscal year t-1 divided by market value of equity.

LOSS: We use a dummy variable $L O S S=1$ for firms with net loss in fiscal year $\mathrm{t}-1$, and 0 otherwise.

\section{DATA, DESCRIPTIVE STATISTICS AND RESULTS}

\section{Data}

The original sample includes all recommendations on the I/B/E/S database for US firms from 1993 to 2014 issued by analysts who can be identified to a brokerage firm. For each analyst-firm-recommendation observation in this sample, we require an annual earnings forecast and annual cash flow forecast issued by the same analyst for the same firm within 30 days prior to and including the date of the recommendation for the firm. ${ }^{14}$ For each firm-year, we require the firm to be followed by at least three analysts during the 
calendar year. In addition, we retain a given analyst-firm-recommendation observation only if the analyst issues at least three forecasts for the firm during a calendar year. To avoid the problem of stale forecasts/recommendations, we do not include forecasts that were issued before the announcement of year t-1's actual earnings. We use the CRSP data to compute stock returns. To reduce the effects of outliers, observation in the top and bottom $0.5 \%$ of all continuous variables are winsorized. The final sample consists of 42,578 recommendations by 3,161 analysts with 3,271 unique firms during the period from 1993 to 2014.

\section{Descriptive Statistics}

Table 1 presents descriptive statistics of the variables. The statistics are based on 42,578 recommendations that are issued with earnings forecasts and cash flow forecasts within 30 days ending on the recommendation date by the same analyst for the same firm. ${ }^{15}$ Of the 42,578 observations in the pooled sample, on average these recommendations generate an overall mean (median) abnormal return to recommendations of $1.9 \%(1.5 \%)$ during the 30-day period, which is comparable with Ertimur et al. (2007). The mean (median) of the relative earnings forecast accuracy is $0.138(0.295)$ which is greater than the mean (median) of 0.067 (0.062) as reported in Ertimur et al. (2007), possibly because analyst earnings forecasts are more accurate when accompanied by cash flow forecasts (Call et al., 2009). The mean (median) of the relative cash flow forecast accuracy, however, is lower at $0.052(0.072)$. This is consistent with prior literature that finds analysts' cash flow forecasts are on average less accurate than their earnings forecasts (Givoly et al., 2007). On average an analyst issues 7 earnings forecasts and 2 recommendations during a calendar year for each firm followed. Analysts' firm specific experience averages around 4 years. The analysts in our sample follow an average of 16 firms and work for brokerage houses that have an average of 95 analysts (c.f. Ertimur et al., 2007). The firms in our sample have close to 17 analysts following them in a given calendar year.

TABLE 1 DESCRIPTIVE STATISTICS

\begin{tabular}{rrrrrrr} 
Variable & N & Mean & Q1 & Median & \multicolumn{1}{c}{ Q3 } & Std Dev \\
\hline PFT & 42,578 & 0.019 & -0.056 & 0.015 & 0.091 & 0.137 \\
PMEFA & 42,578 & 0.138 & -0.105 & 0.295 & 0.660 & 0.766 \\
PMCFA & 42,578 & 0.052 & -0.199 & 0.072 & 0.486 & 0.623 \\
EFREQ & 42,578 & 7.520 & 5.000 & 7.000 & 10.000 & 3.594 \\
RECFREQ & 42,578 & 2.007 & 1.000 & 2.000 & 3.000 & 1.223 \\
FIRMEXP & 42,578 & 3.816 & 1.000 & 3.000 & 5.000 & 3.386 \\
LFR & 42,578 & 2.425 & 0.205 & 0.750 & 2.111 & 5.245 \\
NFIRM & 42,578 & 16.176 & 10.000 & 15.000 & 21.000 & 9.401 \\
BSIZE & 42,578 & 94.815 & 20.000 & 64.000 & 136.000 & 90.517 \\
NANALYST & 42,578 & 17.326 & 9.000 & 16.000 & 24.000 & 9.620 \\
VR & 42,578 & 0.376 & 0.252 & 0.357 & 0.480 & 0.206 \\
SIZE & 42,578 & 8.484 & 7.943 & 8.484 & 9.059 & 1.259 \\
BTM & 42,578 & 0.501 & 0.348 & 0.501 & 0.532 & 0.273 \\
LOSS & 42,578 & 0.211 & 0.000 & 0.000 & 0.000 & 0.247 \\
\hline This table reports the descriptive statistics for the sample of 42,578 recommendation-forecast \\
observations for the & $1993-2014$ period. All variables except the indicator variables are \\
winsorized at the 1st and 99th percentiles.
\end{tabular}

Journal of Accounting and Finance Vol. 19(5) 2019119 
Table 2 reports the Pearson correlation coefficients for the variables of interest. The table indicates that analysts' earnings forecasts accuracy is positively correlated with their cash flow forecasts accuracy. Both earnings forecast accuracy and cash flow forecast accuracy are significantly positively associated with 30-day returns of the recommended stock. From the analyst characteristic perspective, we find that analysts who issue earnings forecasts more frequently produce more accurate forecasts and profitable recommendations. However, the frequency with which analysts make stock recommendations does not seem to correlate with their forecast accuracy and seems to be even negatively correlated with their recommendation profitability. ${ }^{16}$ As expected, analysts with greater experience issue more accurate forecasts and more profitable recommendations (Clement 1999; Luo and Xie 2012). As documented in previous literature, larger brokerage houses tend to issue more profitable recommendations and higher quality forecasts, presumably because they boast greater resources (Clement and Tse, 2003; Hong and Kubik, 2003). Greater analyst following is associated with more accurate forecasts possibly because of better information environment. On the other hand, recommendations are less profitable for firms with high analyst following possibly because competition among analysts drives down the profits (Ertimur et al., 2007). Finally, stock recommendations are more profitable for firms with higher earnings value relevance, smaller size, and negative earnings. 


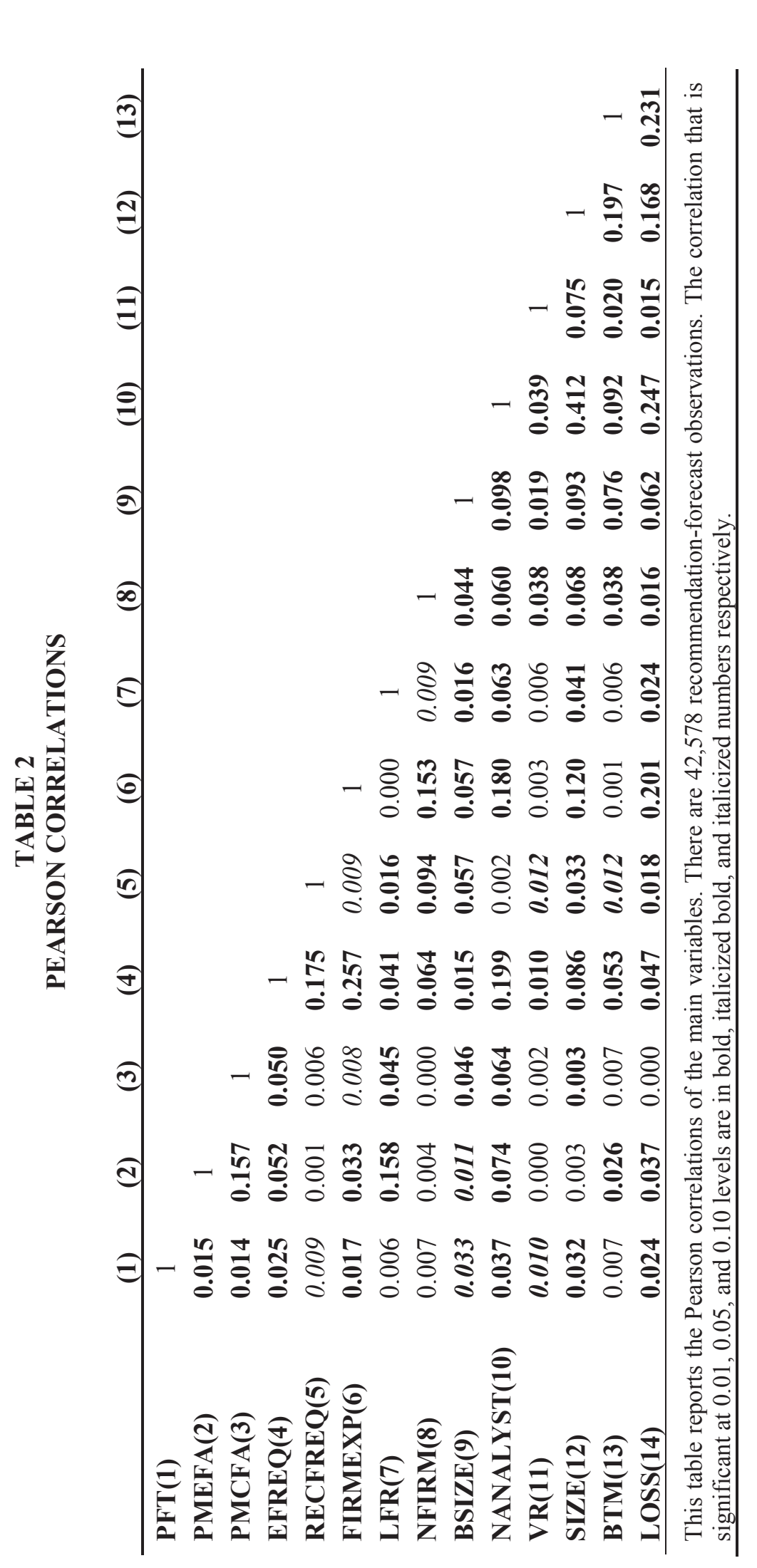




\section{Test of Hypotheses}

The first hypothesis predicts that there exists a positive relation between analysts' supplementary cash flow forecast accuracy and their stock recommendation profitability. Table 3 presents the results of estimating a pooled regression of stock recommendation profitability on forecast accuracy controlling for relevant factors and industry and year fixed effects. We report t-statistics based on standard errors clustered by analyst. The results suggest that when either earnings forecast accuracy or cash flow forecast accuracy enters the regression together with the control variables, the coefficient is significant for earnings forecast accuracy (Coeff. $=0.162$, t-statistic $=1.97$, $\mathrm{p}$-value $=0.049$ ) or cash flow forecast accuracy (Coeff. $=0.263$, t-statistic $=2.57$, $p$-value $=0.010)$. It is consistent with the intuition that when analysts make more accurate forecasts, their inputs to the valuation model are of higher quality, which can assist them in identifying stocks that can generate positive returns. Interestingly, when both earnings forecast accuracy and cash flow forecast accuracy are included in the regression, the coefficient on the earnings forecast accuracy becomes statistically insignificant (Coeff. $=0.129$, $\mathrm{t}$-statistic $=1.55, \mathrm{p}$-value $=0.121$ ) whereas the coefficient on the cash flow forecast accuracy remains significant (Coeff. $=0.236, t$-statistic $=2.27, p$ value $=0.023$ ). This result suggests that in cases where analysts issue both earnings forecasts and cash flow forecasts, cash flow forecast accuracy but not earnings forecast accuracy contributes to more profitable recommendations.

Turning to the control variables. As expected, earnings forecast frequency is positively associated with stock recommendation returns. However, frequent recommendations are negatively associated with their profitability. Consistent with our expectations, firm specific forecast experience and brokerage house size are both positively associated with recommendation returns. Lead analyst is also able to generate more profitable recommendations. On the other hand, number of firms followed by an analyst is negatively related to profitability, albeit not statistically significant. Consistent with the Pearson/Spearman correlations, analyst following is negatively associated with recommendation profitability. The fact that most of the control variables have the appropriate sign lends credence to our results. 


\section{REGRESSION OF ANALYST EARNINGS AND CASH FLOW FORECAST ACCURACY ON RECOMMENDATION PROFITABILITY}

\begin{tabular}{|c|c|c|c|c|c|c|}
\hline & \multicolumn{6}{|c|}{ Dependent Variable: PFT } \\
\hline & \multicolumn{2}{|c|}{ Model 1} & \multicolumn{2}{|c|}{ Model 2} & \multicolumn{2}{|c|}{ Model 3} \\
\hline & Coefficient & t-statistic & Coefficient & t-statistic & Coefficient & t-statistic \\
\hline Intercept & 2.729 & 0.45 & 2.701 & 0.44 & 2.684 & 0.44 \\
\hline PMEFA & $0.162 * *$ & 1.97 & & & 0.129 & 1.55 \\
\hline PMCFA & & & $0.263 * * *$ & 2.57 & $0.236 * *$ & 2.27 \\
\hline EFREQ & $0.086^{* *}$ & 2.36 & $0.088 * *$ & 2.42 & $0.086^{* *}$ & 2.38 \\
\hline RECFREQ & $-0.118 * *$ & -1.96 & $-0.119 * *$ & -1.99 & $-0.118 * *$ & -1.96 \\
\hline FIRMEXP & $0.066 * * *$ & 3.22 & $0.067 * * *$ & 3.24 & $0.066 * * *$ & 3.23 \\
\hline LFR & $0.037 * * *$ & 2.77 & $0.038 * * *$ & 2.88 & $0.037 * * *$ & 2.75 \\
\hline NFIRM & -0.010 & -1.12 & -0.010 & -1.09 & -0.010 & -1.10 \\
\hline BSIZE & $0.003 * * *$ & 2.62 & $0.003 * * *$ & 2.63 & $0.003 * * *$ & 2.64 \\
\hline NANALYST & $-0.034 * * *$ & -3.81 & $-0.034 * * *$ & -3.81 & $-0.035^{* * *}$ & -3.84 \\
\hline VR & 0.522 & 1.56 & 0.521 & 1.55 & 0.521 & 1.56 \\
\hline SIZE & -0.253 & -3.80 & $-0.253 * * *$ & -3.79 & $-0.252 * * *$ & -3.78 \\
\hline BTM & 0.097 & 0.30 & 0.096 & 0.30 & 0.103 & 0.32 \\
\hline LOSS & $0.688 * * *$ & 4.36 & $0.685 * * *$ & 4.34 & $0.684 * * *$ & 4.34 \\
\hline Industry Fixed Effects & & Yes & & Yes & & Yes \\
\hline Year Fixed Effects & & Yes & & Yes & & Yes \\
\hline $\mathrm{N}$ & & 42,578 & & 42,578 & & 42,578 \\
\hline $\mathrm{R}^{2}$ & & $7.68 \%$ & & $7.75 \%$ & & $7.79 \%$ \\
\hline
\end{tabular}

This table presents the results of the Ordinary Least Square (OLS) estimation in the regression of forecast accuracy on stock recommendation profitability for a pooled sample of 42,578 recommendation-forecast pairs. Coefficient is multiplied by 100 to facilitate presentation. t-statistics are based on standard errors clustered by analyst. All variables except the indicator variables are winsorized at the 1st and 99th percentiles.

$* * *, * *, *$ indicates significance at $1 \%, 5 \%$, and $10 \%$ (two-tailed), respectively.

Our second hypothesis suggests that the relationship between analysts' cash flow forecast accuracy and stock recommendation profitability differs across regulation regimes. Specifically, we expect that the relationship to be stronger in the post regulation period. Table 4 reports the regression results. As can be seen from the table, neither earnings forecast accuracy nor cash flow forecast accuracy is significantly associated with stock recommendation profitability in the pre-regulation period. The coefficient on PMEFA (PMCFA) x PRE_REG is $0.171(0.203)$ in Model 1 (2), with a t-statistic of $0.45(0.58)$ and pvalue of $0.650(0.559)$. This result is consistent with prior findings that various analyst incentives affect the effectiveness of translating their forecasts into profitable recommendations (Michaely and Womack, 1999; Barber, Lehavy, and Trueman, 2007). The positive relation between forecast accuracy and recommendation profitability exits mainly in the post-regulation era. The coefficient on PMEFA (PMCFA) x POST_REG is 0.191(0.273) in Model 1 (2), with a t-statistic of 1.99(2.62) and p-value of 0.046 (0.009). Consistent with our findings in the previous analysis, cash forecast accuracy dominates earning forecast accuracy in predicting profitable recommendations in Model (3), with a coefficient of 0.245 on PMCFA x POST_REG (t-statistic $=2.32$, p-value $=0.020)$ and a coefficient of 0.170 on PMEFA $x$ POST_REG(t-statistic $=0 . \overline{43}, \quad \mathrm{p}$-value $=0.599)$. More importantly, the coefficient on PMCFA $\mathrm{x}$ POST_REG is significantly more positive than that of PMCFA x POST_REG, $($ diff $=0.245-0.138=0.107$, 
F-statistic $=3.93$, $p$-value $=0.045$ ). In other words, the results support our hypothesis that the relationship between cash flow forecast accuracy and stock recommendation profitability is stronger in the postregulation period.

\section{TABLE 4 \\ THE RELATION BETWEEN CASH FLOW FORECAST ACCURACY AND RECOMMENDATION PROFITABILITY ACROSS THE REGULATION REGIMES}

\begin{tabular}{|c|c|c|c|c|c|c|}
\hline & \multicolumn{6}{|c|}{ Dependent Variable: PFT } \\
\hline & \multicolumn{2}{|c|}{ Model 1} & \multicolumn{2}{|c|}{ Model 2} & \multicolumn{2}{|c|}{ Model 3} \\
\hline & Coefficient & t-statistic & Coefficient & t-statistic & Coefficient & t-statistic \\
\hline PMEFA x PRE_REG & 0.171 & 0.45 & & & 0.122 & 0.33 \\
\hline PMEFA x POST_REG & $0.191 * *$ & 1.99 & & & 0.170 & 0.53 \\
\hline PMCFA x PRE_REG & & & 0.203 & 0.58 & 0.138 & 1.59 \\
\hline PMCFA x POST_REG & & & $0.273 * * *$ & 2.62 & $0.245^{* * *}$ & 2.32 \\
\hline EFREQ & 0.119 & 0.45 & $0.119 * * *$ & 5.24 & $0.118 * * *$ & 5.20 \\
\hline RECFREQ & $-0.119^{* *}$ & 1.99 & $-0.121 * *$ & -2.01 & $-0.119 * *$ & -1.97 \\
\hline FIRMEXP & $0.066^{* * *}$ & 5.24 & $0.066 * * *$ & 3.19 & $0.066 * * *$ & 3.18 \\
\hline LFR & $0.040 * * *$ & -2.97 & $0.041 * * *$ & 3.06 & $0.040 * * *$ & 2.91 \\
\hline NFIRM & $-0.011 * * *$ & -1.28 & -0.011 & -1.24 & -0.011 & -1.25 \\
\hline BSIZE & $0.003 * * *$ & 2.81 & $0.003 * * *$ & 2.81 & $0.003 * * *$ & 2.82 \\
\hline NANALYST & $-0.034 * * *$ & -3.73 & $-0.034 * * *$ & -3.73 & $-0.035^{* * *}$ & -3.76 \\
\hline VR & $0.604^{*}$ & 1.78 & $0.604 *$ & 1.78 & $0.603 *$ & 1.78 \\
\hline SIZE & $-0.246 * * *$ & -3.64 & $-0.245^{* * *}$ & -3.63 & $-0.245^{* * *}$ & -3.63 \\
\hline BTM & 0.049 & 0.15 & 0.049 & 0.15 & 0.056 & 0.17 \\
\hline LOSS & $0.698 * * *$ & 4.37 & $0.694 * * *$ & 4.36 & $0.694 * * *$ & 4.35 \\
\hline Industry Fixed Effects & & Yes & & Yes & & Yes \\
\hline Year Fixed Effects & & Yes & & Yes & & Yes \\
\hline $\mathrm{N}$ & & 41,731 & & 41,731 & & 41,731 \\
\hline $\mathrm{R}^{2}$ & & $7.41 \%$ & & $7.47 \%$ & & $7.53 \%$ \\
\hline
\end{tabular}

This table presents the results of the Ordinary Least Square (OLS) estimation in the regression of forecast accuracy on stock recommendation profitability for a pooled sample of 41,731 recommendation-forecast pairs across the regulation regimes. PRE_REG=1 for recommendations issued on or before Oct 22, 2000 and 0 otherwise. POST_REG=1 for recommendations issued on or after May 10, 2002 and 0 otherwise. Coefficient is multiplied by 100 to facilitate presentation. t-statistics are based on standard errors clustered by analyst.

$* * *, * *, *$ indicates significance at $1 \%, 5 \%$, and $10 \%$ (two-tailed), respectively.

\section{ROBUSTNESS CHECK AND ADDITIONAL ANALYSES}

\section{Test of Endogeneity}

It is possible that analysts who issue more accurate cash flow forecasts can make more profitable recommendations simply because of their innate ability and/or other unobserved characteristics. As a result, endogeneity could be of concern despite our control of analyst characteristics including their forecasting experiences and forecasting efforts. To address the possibility that unobservable correlated omitted variables are driving our primary results, we undertake additional analysis using instrumental variables techniques. ${ }^{17}$ Specifically, we draw on Pae and Yoon (2012) and use an analyst's cash flow forecast frequency (CFFreq), defined as the number of cash flow forecasts issued by analyst $i$ for firm $j$ in 
year $t$, and cash flow forecast horizon (CFHorizon), defined as the number of days from the forecast date to the fiscal year-end date as instruments for analyst cash flow forecast accuracy (PMCFA). We chose CFFreq and CFHorizon as instruments for PMCFA because Pae and Yoon (2012) document that these two variables are significant both in their correlations with PMCFA and in their coefficients in the regression model. ${ }^{18}$

We undertake several specification tests to check that our instruments are valid and appropriate. ${ }^{19}$ First, we conduct the Hansen-Sargan test to examine that the instruments that we use are valid in the sense that they are not correlated with the regression error term. The test shows that Hansen's J $\chi^{2}(1)$ is 2.565 with $\mathrm{p}$-value $=0.11$, therefore we fail to reject the null hypothesis that the instruments are valid. Second, we carry out the first-stage partial F-test to detect the presence of weak-instrument problems. The result shows that the F-statistic on the join significance of the instruments excluded from the structural model is 143.3 , which is considerable larger than the rule of thumb value of 11.59 for two instruments as suggested by Stock et al. (2002). Therefore, CFFreq and CFHorizon do not seem to be weak instruments. Given the above evidence that CFFreq and CFHorizon seem to be the appropriate instruments for PMCFA, we run the two-stage least square regression using these two instruments. ${ }^{20} \mathrm{We}$ find that the coefficient on PMCFA continues to be positive and significant (Coefficient=0.287, z-statistic=1.98, pvalue $=0.048$ ), suggesting that our results are robust to the unobservable correlated omitted variables.

\section{Changes in Stock Recommendations}

In our main analysis, we use the profitability of stock recommendation levels as the dependent variable. However, analyst recommendations can be "sticky" as analysts tend to reiterate their previous recommendations without any change in levels (Asquith et al., 2005; Francis and Soffer, 1997). To examine whether our results are robust to an alternative specification using stock recommendation changes, we rerun model (1) restricting our sample to stock recommendation revisions (Alfonso, 2016). ${ }^{21}$ Specifically, we measure the profitability of upgrade and downgrade stock recommendations (CHANGE_PFT) as the market adjusted return to the recommendation over the period from the day before the recommendation revision date until the earlier of either 30 days or 2 days before the recommendation is revised. We go long (short) in the upgrade (downgrade) recommendations. Table 5 reports the results using the profitability of stock recommendation changes. The results indicate that cash flow forecast accuracy is significantly positively related to the profitability of stock recommendation changes even after controlling for earnings forecast accuracy and other factors (Coeff. $=0.318$, tstatistic $=2.84$, $\mathrm{p}$-value $=0.005$ ) and our main conclusion holds given this alternative measure of stock recommendation profitability. 


\section{TABLE 5}

\section{REGRESSION OF ANALYST EARNINGS AND CASH FLOW FORECAST ACCURACY ON THE PROFITABILITY OF RECOMMENDATION CHANGES}

\begin{tabular}{|c|c|c|c|c|c|c|}
\hline & \multicolumn{6}{|c|}{ Dependent Variable: CHANGE_PFT } \\
\hline & \multicolumn{2}{|c|}{ Model 1} & \multicolumn{2}{|c|}{ Model 2} & \multicolumn{2}{|c|}{ Model 3} \\
\hline & Coefficient & t-statistic & Coefficient & t-statistic & Coefficient & t-statistic \\
\hline Intercept & -2.009 & -0.32 & -2.032 & -0.32 & -2.063 & -0.33 \\
\hline PMEFA & $0.237 * * *$ & 2.63 & & & 0.195 & 2.14 \\
\hline PMCFA & & & $0.357 * * *$ & 3.22 & $0.318 * * *$ & 2.84 \\
\hline EFREQ & $0.137 * * *$ & 5.41 & $0.136 * * *$ & 5.40 & $0.135 * * *$ & 5.36 \\
\hline RECFREQ & 0.011 & 0.16 & 0.008 & 0.11 & 0.011 & 0.15 \\
\hline FIRMEXP & $0.175 * * *$ & 6.85 & $0.175 * * *$ & 6.86 & $0.175 * * *$ & 6.86 \\
\hline LFR & $0.047 * * *$ & 2.92 & $0.049 * * *$ & 3.06 & $0.047 * * *$ & 2.89 \\
\hline NFIRM & -0.005 & -0.47 & -0.005 & -0.43 & -0.005 & -0.44 \\
\hline BSIZE & $0.004 * * *$ & 3.30 & $0.004 * * *$ & 3.31 & $0.004 * * *$ & 3.32 \\
\hline NANALYST & 0.001 & 0.10 & 0.001 & 0.11 & 0.001 & 0.06 \\
\hline VR & 0.355 & 1.01 & 0.356 & 1.01 & 0.355 & 1.01 \\
\hline SIZE & $-0.382 * * *$ & -4.83 & $-0.381 * * *$ & -4.82 & $-0.380 * * *$ & -4.81 \\
\hline ВТМ & -0.290 & -0.86 & -0.289 & -0.85 & -0.280 & -0.83 \\
\hline LOSS & 0.296 & 1.63 & 0.290 & 1.59 & 0.290 & 1.60 \\
\hline Industry Fixed Effects & & Yes & & Yes & & Yes \\
\hline Year Fixed Effects & & Yes & & Yes & & Yes \\
\hline $\mathrm{N}$ & & 36,767 & & 36,767 & & 36,767 \\
\hline $\mathrm{R}^{2}$ & & $12.80 \%$ & & $12.80 \%$ & & $12.71 \%$ \\
\hline
\end{tabular}

This table presents the results of the Ordinary Least Square (OLS) estimation in the regression of forecast accuracy on the profitability of revised stock recommendation for a pooled sample of 36,767 recommendation-forecast pairs. CHANGE_PFT is the profitability of upgrade and downgrade recommendations measured as market adjusted return to the recommendation over the period from the day before the recommendation revision date until the earlier of either 30 days or 2 days before the recommendation is revised again. For downgrade recommendations, we multiply the return by -1 . Coefficient is multiplied by 100 to facilitate presentation. $t$-statistics are based on standard errors clustered by analyst. All variables except the indicator variables are winsorized at the 1st and 99th percentiles.

$* * *, * *, *$ indicates significance at $1 \%, 5 \%$, and $10 \%$ (two-tailed), respectively.

\section{Control for Other Supplementary Forecasts}

We include two other supplementary forecasts, sales forecasts and long-term growth forecasts, as controls based on prior research that has found them signaling analyst efforts and ability (Keung, 2010; Jung et al, 2012). Specifically, $\mathrm{SFI}=1$ if an analyst issues a sales forecast within 30 days prior to and including the issue date of the recommendation for a firm, and 0 otherwise; and LTGI=1 if an analyst issues a long-term growth forecast within 180-day prior to and including the issue date of the recommendation for a firm, and 0 otherwise (Jung et al, 2012). The results are reported in Table 6. Neither of the coefficients for SFI or LTGI is statistically significant, suggesting that the presence of neither sales forecasts nor long-term growth forecasts is associated with stock recommendation profitability when cash flow forecasts are also issued. Our main results remain qualitatively the same. 
TABLE 6

EFFECTS OF OTHER SUPPLEMENTARY FORECASTS ON THE RELATION BETWEEN FORECAST ACCURACY AND RECOMMENDATION PROFITABILITY

\begin{tabular}{|c|c|c|c|c|c|c|}
\hline & \multicolumn{6}{|c|}{ Dependent Variable: PFT } \\
\hline & \multicolumn{2}{|c|}{ Model 1} & \multicolumn{2}{|c|}{ Model 2} & \multicolumn{2}{|c|}{ Model 3} \\
\hline & Coefficient & t-statistic & Coefficient & t-statistic & Coefficient & t-statistic \\
\hline Intercept & 2.493 & 0.41 & 2.475 & 0.41 & 2.456 & 0.40 \\
\hline PMEFA & $0.159 *$ & 1.93 & & & 0.126 & 1.51 \\
\hline PMCFA & & & $0.265 * * *$ & 2.59 & $0.239 * *$ & 2.30 \\
\hline SFI & 0.153 & 0.78 & 0.152 & 0.78 & 0.151 & 0.77 \\
\hline LTGI & -0.116 & -0.69 & -0.109 & -0.65 & -0.112 & -0.67 \\
\hline EFREQ & $0.120 * * *$ & 5.42 & $0.120 * * *$ & 5.41 & $0.120 * * *$ & 5.38 \\
\hline RECFREQ & $-0.109 *$ & -1.80 & $-0.111 *$ & -1.84 & -0.109 & -1.81 \\
\hline FIRMEXP & $0.065 * * *$ & 3.14 & $0.065^{* * *}$ & 3.16 & 0.065 & 3.15 \\
\hline LFR & $0.038 * * *$ & 2.83 & $0.039 * * *$ & 2.93 & $0.038 * * *$ & 2.80 \\
\hline NFIRM & -0.011 & -1.23 & -0.011 & -1.20 & -0.011 & -1.20 \\
\hline BSIZE & $0.003 * * *$ & 3.15 & $0.003 * * *$ & 3.14 & $0.003 * * *$ & 3.15 \\
\hline NANALYST & $-0.034 * * *$ & -3.77 & $-0.034 * * *$ & -3.77 & $-0.034 * * *$ & -3.80 \\
\hline VR & 0.519 & 1.55 & 0.518 & 1.55 & 0.518 & 1.55 \\
\hline SIZE & $-0.251 * * *$ & -3.76 & $-0.251 * * *$ & -3.75 & $-0.250 * * *$ & -3.74 \\
\hline BTM & 0.097 & 0.30 & 0.097 & 0.30 & 0.103 & 0.32 \\
\hline LOSS & $0.685 * * *$ & 4.33 & $0.681 * * *$ & 4.32 & $0.681 * * *$ & 4.31 \\
\hline Industry Fixed Effects & & Yes & & Yes & & Yes \\
\hline Year Fixed Effects & & Yes & & Yes & & Yes \\
\hline $\mathrm{N}$ & & 42,578 & & 42,578 & & 42,578 \\
\hline $\mathrm{R}^{2}$ & & $7.73 \%$ & & $7.77 \%$ & & $7.82 \%$ \\
\hline
\end{tabular}

This table presents the results of the Ordinary Least Square (OLS) estimation in the regression of forecast accuracy on stock recommendation profitability controlling for analysts' other supplementary forecasts including sales forecasts and long-term growth forecasts. SFI $=1$ if an analyst issues a sales forecast within 30 days prior to and including the issue date of the recommendation for a firm, and 0 otherwise; and LTGI $=1$ if an analyst issues a longterm growth forecast within 180-day prior to and including the issue date of the recommendation for a firm, and 0 otherwise. Coefficient is multiplied by 100 to facilitate presentation. t-statistics are based on standard errors clustered by analyst. All variables except the indicator variables are winsorized at the 1st and 99th percentiles.

$* * *, * *, *$ indicates significance at $1 \%, 5 \%$, and $10 \%$ (two-tailed), respectively.

\section{CONCLUSION}

Analysts issue supplementary cash flow forecasts to facilitate investors' firm valuation (Defond et al., 2003). However, limited evidence exists as to whether these supplementary cash flow forecasts assist analysts themselves in their investment recommendations. Research using consensus cash flow forecasts or issuance of cash flow forecasts fails to document a significant relation between analysts' cash flow forecasts and stock recommendation performance (Duboisée de Ricquebourg and Clacher, 2017; Jung et al., 2012). We argue that analysts' cash flow forecasts differ in quality and propose to examine the relation between analysts' cash flow forecasts and stock recommendation profitability at the individual level. We find that when analysts issue both earnings forecasts and cash flow forecasts, cash flow forecast accuracy dominates earnings forecast accuracy in predicting profitable recommendations. This finding refines our understanding on the link between analysts' earnings forecast accuracy and their stock 
recommendation performance established in prior literature. Furthermore, despite prior findings that analysts' cash flow forecasts on average are of lower quality than earnings forecasts, this study shows that high quality cash flow forecasts from individual analysts can be useful in identifying better performing stocks.

The results suggest that future studies examining analysts' cash flow forecasts at the individual level could be fruitful. For instance, research could explore the cash flow models by individual analysts and investigate whether and how cash flow forecasts are used in a more sophisticated manner by more accurate forecasters in assessing firm values. The findings also suggest that when analysts issue both earnings forecast and cash flow forecasts for a firm, investors could use analysts' cash flow forecast quality as a more direct signal to identify profitable stock recommendations.

\section{ENDNOTES}

1. In untabulated analysis, we also confirm that the issuance or existence of cash flow forecasts is not associated with stock recommendation profitability.

2. Call et al. (2009) actually argues that the issuance of cash flow forecasts itself requires analysts to analyze a firm's financial statements and earnings components in details. Given the evidence that individual differences exist in analyst cash flow forecasting skills and abilities (Pae and Yoon 2012), we believe that high quality cash flow forecasts are more likely to reflect analysts' greater forecasting efforts and competence.

3. The evidence that brokerage firms put significant value on the recommendations they produce is illustrated in the lawsuit by several major brokerage houses over an internet news service' unauthorized distribution of their newly issued stock recommendations to non-clients. See Li, Ramesh, Shen and Wu (2015) for details.

4. It would be interesting to examine the valuation models that individual analysts use to transform cash flow fore- casts into stock recommendations. We leave this question for future research.

5. For an extensive review on analysts' forecasts and stock recommendations, see Ramneth, Rock and Shane (2008). Also see Schipper (1991) and Brown (1993) for earlier reviews on analysts' research.

6. The first year I/B/E/S included cash flow forecasts was 1993.

7. Call et al. (2009) document that issuing cash flow forecasts improves analysts' earnings forecast accuracy, which makes their earnings forecasts more informative. They do not, however, directly examine whether cash flow forecasts can facilitate stock recommendations beyond earnings forecasts.

8. We did not examine how conflict of interest affects the relationship between cash flow forecast accuracy and stock recommendation profitability and expect such conflict should bias against us finding results. Future research could examine whether the cash flow forecast accuracy and recommendation performance relationship differs between conflicted and non-conflicted analysts, in the same vein as in Ertimur et al. (2007).

9. Analyst, firm and forecast subscripts are omitted for brevity.

10. Our research design requires both earnings forecasts and cash flow forecasts issued along with a recommendation to be to be included in the sample. An alternative research design is to require recommendations to have accompanying cash flow forecasts, with or without earnings forecasts. We choose to require both to provide a benchmark against the earnings forecast accuracy test in Ertimur et al. (2007). In addition, cash flow forecasts are typically accompanied with earnings forecasts. In untabulated analysis, we find that over $99 \%$ of analysts who issued a cash flow forecasts for a firm also issued an earnings forecast for the same forecast date, $90 \%$ of them issued an earnings forecast within 30 days, $77 \%$ of them issued an earnings forecast on the same date. When we expand our sample to all recommendations with accompanying cash flow forecasts regardless of the presence of the earnings forecasts, we continue to find cash flow forecast accuracy to be positively associated with recommendation profitability.

11. Using equally weighted market-adjusted returns yields qualitatively similar results.

12. Prior literature finds that information in stock recommendations is impounded in prices over a 60-day period, with most of the price adjustment occurring in the first 30 days immediately following the issuance of stock recommendations (Jegadeesh et al., 2004; Stickel, 1995). In unreported analyses we used both a shorter window $(-2,2)$ and a longer window $(-1,60)$, the results remain qualitatively the same.

13. In the case where analyst $\mathrm{i}$ issues forecasts for multiple fiscal period end dates during the 30 -day period, we choose those that are issued for the first earnings announcement date that falls after the recommendation date. 
14. We restrict our analysis to annual forecasts because the majority of $\mathrm{I} / \mathrm{B} / \mathrm{E} / \mathrm{S}$ cash flow forecasts are annual. Untabulated results show that between 1993-2002, the percentage of firms with quarterly cash flow forecasts increased gradually from close to 0 to $3 \%$; in 2003 the percentage of firms with quarterly cash flow forecasts increased significantly to around $8 \%$ and has since remained between $10 \%-13 \%$ of firms.

15. When stock recommendations, earnings forecasts and cash flow forecasts are issued by the same analyst within 30 days, it is more likely that the stock recommendations are based on the analyst' earnings forecasts and cash flow forecasts.

16. Bernhardat et al. (2016) argue that analysts resist revising their recommendations frequently to signal the credibility of their initial recommendations and protect their reputations. As a result, frequent recommendation revisions cast doubt on the ability of the analysts to make profitable recommendations.

17. Other commonly used techniques to address the endogeneity issue include the propensity-score matching method and the Heckman (1979) selection model. However, neither method is applicable here because both methods require the endongenous variable to be an indicator variable whereas in our model the variable of interest (PMCFA) is a continuous variable (Lennox et al., 2012).

18. Pae and Yoon (2012) developed a model that includes eight variables as determinants of an analyst's cash flow forecast accuracy. In addition to CFFreq and CFHorizon, other variables that are strongly correlated with PMCFA are forecasting experience (FirmExp) and brokerage house size (BSize). We chose not to use FirmExp and BSize because both are included in our model for recommendation profitability. For instrument variables to be valid, they should be strongly correlated with the instrumented variable (PMCFA) but should not be explanatory variables for recommendation profitability (PFT) (Greene, 2008).

19. All the tests and IV regressions are clustered by analyst as in the main analysis.

20. We also perform the Durbin-Wu-Hausman $(\mathrm{DWH})$ test of endogeneity and find that robust regression $\mathrm{F}$ statistic $=1.52(p=0.22)$. Therefore, we fail to reject the null hypothesis that PMCFA is exogenous. In other words, to the extent that our instrument variables are valid and appropriate, we do not find evidence that PMCFA is endongenous. Nonetheless, we still present the results using the instrument variables as a robustness check and note that in this case the OLS estimates are more efficient.

21. We treat the initiation of a recommendation as a recommendation revision.

\section{REFERENCES}

Alfonso, E. (2016). Stock Recommendations for Politically Connected Firms. Journal of Business Finance and Accounting, 43, 448-486.

Ali, A. (1994). The incremental information content of earnings, working capital from operations, and cash flows. Journal of Accounting Research, 32, 61-74.

Asquith, P., Mikhail, M., \& Au, A. (2005). Information content of equity analyst reports. Journal of Financial Economics, 75, 245-282.

Barber, B.M., Lehavy, R., \& Trueman, B. (2007). Comparing the stock recommendation performance of investment banks and independent research firms. Journal of Financial Economics, 85, 490-517.

Barniv, R., Hope, O.-K., Myring, M.J., \& Thomas, W.B. (2009). Do analysts practice what they preach and should investors listen? Effects of recent regulations. The Accounting Review, 84, 1015-1039.

Barniv, R., Hope, O-K., Myring, M.J., \& Thomas, W.B. (2010). International evidence on analyst stock recommendations, valuations, and returns. Contemporary Accounting Research, 27, 1131-1167.

Bernhardat, D., Wan, C., \& Xiao, Z. (2016). The reluctant analyst. Journal of Accounting Research, 54, 987-1040.

Bradshaw, M.T. (2004). How do analysts use their earnings forecasts in generating stock recommendations? The Accounting Review, 79, 25-50.

Brown, L. (1993). Earnings forecasting research: its implications for capital markets research. International Journal of Forecasting, 9, 295-320.

Brown, L., \& Huang, K. (2013). Forecast -recommendation consistency and earnings forecast quality. Accounting Horizons, 27, 451-467.

Call, A.C., Chen, S., \& Tong, Y.H. (2009). Are analysts' earnings forecasts more accurate when accompanied by cash flow forecasts? Review of Accounting Studies, 14, 358-391. 
Call, A.C., Chen, S., \& Tong, Y.H. (2013). Are analysts' cash flow forecasts naïve extensions of their own earnings forecasts? Contemporary Accounting Research, 30, 438-465.

Chen, C-Y., \& Chen, P.F. (2009). NASD Rule 2711 and changes in analysts' independence in making stock recommendations. The Accounting Review, 84, 1041-1071.

Clement, M.B. (1999). Analyst forecast accuracy: Do ability, resources, and portfolio complexity matter? Journal of Accounting and Economics, 27, 285-303.

Clement, M. B., \& Tse, S. V. (2003). Do investors respond to analysts' forecast revisions as if forecast accuracy is all that matters? The Accounting Review, 78, 27-249.

Cooper, R.A., Day, T.E., \& Lewis, C.M. (2001). Following the leader: A study of individual analysts earnings forecasts. Journal of Financial Economics, 61, 383-416.

Das, S., Levin, C.B., \& Sivaramakrishnan, K. (1998). Earnings predictability and bias in analysts'earnings forecasts. The Accounting Review, 73, 277-294.

Dechow, P.M. (1994). Accounting earnings and cash flows as measures of firm performance: The role of accounting accruals. Journal of Accounting and Economics, 18, 3-42.

Dechow, P.M., Hutton, A.P., \& Sloan, R. G. (2000). The relation between analysts' forecasts of long-term earnings growth and stock price performance following equity offerings. Contemporary Accounting Research, 17, 1-32.

DeFond, M.L. \& Hung, M. (2003). An empirical analysis of analysts' cash flow forecasts. Journal of Accounting and Economics, 35, 73-100.

Duboisée de R., Alan J., \& Clacher, I. (2017). Analyst stock recommendations, cash flow valuations, and stock return profitability. working paper, SSRN: https://ssrn.com/abstract $=2657078$ or http://dx.doi.org/10.2139/ssrn.2657078.

Dugar, A., \& Nathan, S. (1995). The effect of investment banking relationships on financial analysts' earnings forecasts and investment recommendations. Contemporary Accounting Research, 12, 131-160.

Ertimur, Y., \& Stubben, S. (2005). Analysts' incentives to issue revenue and cash flow forecasts. Working paper, Stanford University.

Ertimur, Y., Sunder, J., \& Sunder, S.V. (2007). Measure for measure: the relation between forecast accuracy and recommendation profitability of analysts. Journal of Accounting Research, 45, 567606.

Francis, J., \& Philbrick, D. (1993). Analysts' decisions as products of a multi-task environment. Journal of Accounting Research, 31, 216-230.

Francis, J. \& Soffer, L. (1997). The relative informativeness of analysts' stock recommendations and earnings forecast revisions. Journal of Accounting Research, 35, 193-211.

Greene, W. (2008). Econometric analysis. Upper Saddle River, NJ: Pearson/Prentice Hall.

Givoly, D., Hayn, C., \& Lehavy, R. (2009). The quality of analysts' cash flow forecasts. The Accounting Review, 84, 1877-1911.

Hong, H., \& Kubik, J. D. (2003). Analyzing the Analysts: Career Concerns and Biased Earnings Forecasts. Journal of Finance, 58, 313-351.

Jacob, J., Lys, T.Z., \& Neale, M. A. (1999). Expertise in forecasting performance of security analysts. Journal of Accounting \& Economics, 28, 51-82.

Jegadeesh, N., Kim, S., Krische, D., \& Lee, C. M. C. (2004). Analyzing the analysts: when do recommendations add value? Journal of Finance, 59, 1083-1124.

Jung, S.W. (2015). Are analysts' cash flow forecasts useful? Accounting and Finance, 55, 825-859.

Jung, B., Shane, P.B., \& Yang, S.Y. (2012). Do financial analysts' long-term growth forecasts matter? Evidence from stock recommendations and career outcomes. Journal of Accounting and Economics, 53, 55-76.

Ke, B., \& Yu, Y. (2006). The effect of issuing biased earnings forecasts on analysts' access to management and survival. Journal of Accounting Research, 44, 965-999.

Keung, E.C. (2010). Do supplementary sales forecasts increase the credibility of financial analysts' earnings forecasts? The Accounting Review, 85, 2047-2074. 
Lang, M.H., \& Lundholm, R.J. (1996). Corporate disclosure policy and analyst behavior. The Accounting Review, 71, 467-492.

Lennox, C.S., Frances, J. R., \& Wang, Z. (2012). Selection models in accounting research. The Accounting Review, 87, 589-616.

Li, E. X., Ramesh, K., Shen, M., \& Wu, J. S. (2015). Do analyst stock recommendations piggyback on recent corporate news? An analysis of regular-hour and after-hours revisions. Journal of Accounting Research, 53, 821-861.

Lin, H-W., \& McNichols, M.F. (1998). Underwriting relationships, analysts' earnings forecasts and investment recommendations. Journal of Accounting and Economics, 25, 101-127.

Loh, R.K., \& Mian, G.M. (2006). Do accurate earnings forecasts facilitate superior investment recommendations? Journal of Financial Economics, 80, 455-483.

Luo, T., \& Xie, W. (2012). Individual differences and analyst forecast accuracy. Review of Accounting and Finance, 11, 257-278.

Mao, M.Q., \& Yu, Y. (2015). Analysts' cash flow forecasts, audit effort, and audit opinions on Internal Control. Journal of Business Finance and Accounting, 42, 635-664.

McInnis, J., \& Collins, D.W. (2011). The effect of cash flow forecasts on accrual quality and benchmark beating. Journal of Accounting and Economics, 51, 219-239.

Michaely, R., \& Womack, K.L. (1999). Conflict of Interest and the Credibility of Underwriter Analyst Recommendations. The Review of Financial Studies, 12, 653-686.

Michaely, R., \& Womack, K. (2005). Brokerage recommendations: Stylized characteristics, market responses, and biases. In Thaler, R., (Ed.), Advances in Behavioral Finance II, Princeton University Press, Princeton, NJ.

Mohanram, P.S. (2014). Analysts' cash flow forecasts and the decline of the accruals anomaly. Contemporary Accounting Research, 31, 1143-1170.

Pae, J., \& Yoon, S-S. (2012). Determinants of analysts' cash flow forecast accuracy. Journal of Accounting, Auditing and Finance, 27, 123-144.

Pae, J., Wang, S., \& Yoo, C. Y. (2007). Do analysts who issue cash flow forecasts predict more accurate earnings? Working paper. Queens University.

Radhakrishnan, S., \& Wu, S-L. (2014). Analysts' cash flow forecasts and accrual mispricing. Contemporary Accounting Research. 31, 1191-1219.

Ramneth, S., Rock, S., \& Shane, P. B. (2008). The financial analyst forecasting literature: a taxonomy with trends for further research. International Journal of Forecasting, 24, 34-75.

Schipper, K. (1991). Commentary on analysts' forecasts. Accounting Horizons, 5, 105-121.

Stickel, S.E. (1995). The anatomy of the performance of the buy and sell recommendations. Financial Analysts Journal, 51, 25-39.

Stock, J. H., Wright, J. H., \& Yogo, M. (2002). A survey of weak instruments and weak identification in generalized method of moments. Journal of Business and Economic Statistics, 20, 518-529. 